\title{
TRANSLITERATION AND Documentation
}

There are always problems to be confronted in using another language in research. I have tried to minimize the difficulties by translating as much as possible from original Greek and Russian sources, but this still leaves the necessity of transliterating proper names and the titles of articles, books, and monographs. For the Russian, I have used the Library of Congress System throughout the text. Modern Greek is more of a problem; for there appears to be no commonly accepted system of transliteration that seeks to minimize the burden on the non-Greek-speaking reader. Indeed, the Chicago Manual of Style deals only with classical Greek; the United States Government Printing Office's Style Manual suggests using a standard transliteration, regardless of pronunciation, but the inclusion of various diacritical marks makes the text tedious and difficult to absorb. Since my primary objective is to have the various Greek citations blend as smoothly into the text as other passages without producing confusion, I have adopted the Style Manual's suggestion but with several important changes. Greek letters are transliterated as follows: a, v, g, d, e, z, i, th, i, $\mathrm{k}, \mathrm{l}, \mathrm{m}, \mathrm{n}, \mathrm{x}, \mathrm{o}, \mathrm{p}, \mathrm{r}, \mathrm{s}, \mathrm{t}, \mathrm{y}, \mathrm{f}, \mathrm{ch}, \mathrm{ps}, \mathrm{o}$. The only exceptions are several vowel-and-consonant combinations in which the sound changes significantly. Hence, " $\epsilon v$ " and " $\alpha v$ " become "ev/ef" and "av/af," respectively; " $\nu \tau$ " becomes " $d$ " at the beginning of words; " $\mu \pi$ " is given as "mb/mp/b"; and " $\gamma \gamma / \gamma \kappa$ " appears as "g/ng."

Even so, transliteration in the text will differ from English-language documents that contain various translations of original Greek sources 
within them. I have left the documents unchanged, but introduced minor changes in brackets where grammatical errors or stylistic differences in the original documents require clarification. This is especially necessary in the excerpts from the Greek Communist archives, because they are replete with aliases, omissions, contractions, and occasional grammatical errors. In all cases, the changes I introduce appear in brackets; parentheses in a citation indicate that the material was in the original source. Preserving the form of the original documents inevitably produces differences in names between the text and quotations. In most instances these are understandable without insertions or corrections, since the variations involve little more than one or two letters. I am confident the reader will be able to recognize that "Zachariades" refers to Nikos Zachariadis, "Themistocles Sophoulis" to Themistoklis Sofoulis, "Ioannides" to Iannis Ioannidis, and so on. Only in cases where it is likely that the original transliteration will be misleading have I inserted appropriate corrections. Prominent place names have been retained in their commonly accepted English transliteration for the reader's convenience.

In many instances, pseudonyms and aliases have been used, and I have provided real names when they are known. The Greek Communists' contacts in the Balkan countries pose a special problem, because in some instances one can ascertain neither nationality nor individual identity. "Zhivkov," for example, is mentioned several times by Zachariadis while he was in Belgrade, but it is as yet impossible to determine conclusively whether Zhivkov is a pseudonym, or even whether he is Soviet or Bulgarian. As a general rule, I have used the names provided in the documents available to me and have indicated the identity of individuals only when I am certain. Where two different spellings appear for what is clearly one person, I have used one in the text and placed the alternative form in an accompanying note.

Another problem arises in citing authors of Greek origin who have published works in languages other than Greek. When those works are in English, I have kept the name as it appears in the published work. Greekname authors in other languages have been transliterated from the language in which the work was published. For example, the author of Grazhdanskaia voina v Gretsii, I946-I949 is given as G. D. Kir'iakidis, despite the fact that having his name transliterated from Greek would yield "Kyriakidis." The same rule applies to non-Greek titles that contain a transliteration different from mine. Finally, in the rare instance when an author has published in both English and Greek using different names, I have provided the name transliterated from the Greek and then bracketed the alternative English spelling. 
Moscow And GreeK

COMMUNISM, I944-I 949 